\title{
OS RUMOS DO FUNDEB
}

Paulo Martins Sena'

${ }^{1}$ Bacharel e mestre em Direito pela USP. Doutor em Educação pela UnB.

Consultor legislativo da Câmara dos Deputados. 
RESUMO: O texto apresenta análise com o objetivo de abordar o legado da política de fundos contábeis iniciada por meio do Fundef e aprimorada com o advento do Fundeb. Aponta as eficiências e insuficiências e, também, avanços, limites e desafios para a construção do novo Fundeb permanente. São destacadas as eficiências inclusiva, redistributiva, federativa e de qualidade do sistema - que têm como elementos, também, a inclusão e a equidade. Destaca-se, ainda, a relevante preferência constitucional pelo ensino público e o princípio constitucional da vinculação de recursos à manutenção e desenvolvimento do ensino, ambos como as bases da identidade constitucional em matéria de educação.

Palavras-Chave: Política de fundos. Fundeb. Fundeb permanente. Valor aluno ano total. Eficiências do Fundeb.

ABSTRACT: The text addresses the legacy of accounting fund policy initiated through Fundef and enhanced with the advent of Fundeb and points out its efficiencies and shortcomings and discuss its advances, limits and challenges for new permanent Fundeb. We highlight the inclusive, redistributive, federative and quality efficiencies of the system - which also consider inclusion and equity. It emphasizes the constitutional preference for public education and the constitutional principle of linking resources to the maintenance and development of education as the foundations of constitutional identity in education.

Keywords: Fundeb. Permanent Fundeb. Total year student value. Fundeb efficiency. Educational fund policy. 


\section{INTRODUÇÃO}

No campo do direito financeiro, o fundo é um conceito que remete à reunião de recursos de diferentes fontes e sua separação para uma destinação específica. Os fundos constituem reservas de certas receitas públicas para a realização de determinados objetivos ou serviços de interesse público (HARADA, 2001).

O Fundo de Manutenção e Desenvolvimento da Educação Básica e de Valorização dos Profissionais da Educação (Fundeb), assim como seu predecessor, (Fundo de Manutenção e Desenvolvimento do Ensino Fundamental e de VaIorização do Magistério (Fundef), é um fundo contábil, que opera por meio de conta única e específica. Não é pessoa jurídica. Não tem administração. Os recursos dos municípios não podem ser retidos pelos estados ou pela União. Não há obstáculos ou condicionalidades - e essa é uma de suas virtudes.

Um fundo dessa natureza constitui "uma rubrica, uma conta, uma referência contábil” (BOTELHO, 2001).

Caracterizam-se como fundos especiais, nos termos da Lei n. ${ }^{\circ}$ 4.320/1964 (BRASIL, 1964, s.p.), que são "produto de receitas especificadas que por lei se vinculam à realização de determinados objetivos ou serviços, facultada a adoção de normas peculiares de aplicação" (art.71) e cujo saldo positivo apurado em balanço será transferido para o exercício seguinte, a crédito do mesmo fundo" (art.73).

Por representarem uma exceção ao princípio de unidade de tesouraria', esses fundos favorecem uma maior transparência, além de viabilizar o fluxo regular de recursos (MARTINS, 2011).

A natureza contábil do fundo permitiu que cada ente subnacional pudesse se planejar diante do novo cenário jurídico-institucional, sem a ameaça de que, por injunções e disputas políticas, gestores de outro ente tivessem a possibilidade de reter ou bloquear recursos, garantidos segundo as matrículas.

A proposta da criação de fundos para gerir os recursos educacionais remonta ao Manifesto dos Pioneiros da Educação Nova (1932), que defendia a instituição de fundo "especial ou escolar", constituído de patrimônios, impostos e rendas próprias, administrado pelos órgãos do ensino (AZEVEDO, 1958). Nos debates que precederam a aprovação da Carta de 1934 - a primeira que continha um capítulo dedicado à educação e que consagrou a vinculação de recursos - a Associação Brasileira de Educação (ABE), que reunia o grupo dos Pioneiros, formulou um conjunto de propostas, por meio da "comissão dos 10", presidida por Anísio Teixeira, que entendia que

Segundo esse princípio, todas as receitas públicas são recolhidas ao Tesouro, para daí saírem somente sob a forma de pagamentos de despesas consignadas no orçamento. Os fundos especiais são exceção a esse princípio e têm suas contas específicas. 
Complemento dessa autonomia administrativa e técnica, é a autonomia financeira que ficou assegurada, no anteprojeto, pela constituição dos fundos de educação

São eles nacional e estaduais e se organizam por meio de impostos especiais e percentagens sobre as rendas da União, dos Estados e dos

Municípios. A medida é de tal importância que se justifica por si mesma. Sem ela, tudo mais não será senão palavra inútil, cuja execução se não poderá garantir. (ABE,1934).

Assim, na proposição da $A B E$, os fundos se organizariam por meio das vinculações:

A redação do texto constitucional, embora representasse uma vitória dos Pioneiros, dissociava a vinculação dos impostos dos fundos, itens que apareciam associados na formulação original da ABE, que entre suas aspirações, tais como formuladas por seu Conselho Diretor, reivindicava:

$\S 5^{\circ}$ - $O$ fundo de educação nacional será constituído de uma percentagem não inferior a 10\% da renda dos impostos da União, de impostos e taxas especiais e outros recursos financeiros eventuais.

A mesma proposição (com diferente percentual - 20\%) era feita para os Estados e para o Distrito Federal (ABE, 1934, p.35).

A adoção de fundos como forma de organização dos recursos vinculados somente seria retomada com o Fundef e, posteriormente, com o Fundeb (MARTINS;PINTO, 2013).

O Fundef, como mecanismo de financiamento, representou, antes de mais nada, a junção num mesmo instrumento, das duas estratégias que apareceram separadas na Constituição de 1934: a vinculação de recursos de impostos e a política de fundos. A diretriz geral da política de financiamento reconciliava-se com a proposta original dos pioneiros da Escola Nova, via Conselho Diretor da ABE. O fundo, concebido para organizar os recursos vinculados, permite que a vinculação cumpra seus objetivos (MARTINS, 2010).

As experiências do Fundef e do Fundeb deixaram um legado importante, em primeiro lugar, no que se refere a desenho de uma política de financiamento da educação básica, na medida em que reuniram como características:

» natureza contábil;

» contas únicas e específicas com automaticidade de repasses;

» âmbito de cada Estado e do DF;

» aplicação de diferentes ponderações para etapas, modalidades e tipos de estabelecimento;

» subvinculação de $60 \%$ dos recursos para os profissionais do magistério (da etapa abrangida); 
controle social e acompanhamento exercido por conselhos nas três esferas federativas;

» destinação a ações de manutenção e desenvolvimento do ensino da educação básica (art.70 da LDB);

" cômputo das matrículas segundo a área de atuação prioritária (função própria - art. 211, CF - regra "cada um no seu quadrado");

» complementação da União.

Essas características já estavam presentes no Fundef. O que o Fundeb fez foi, em primeiro lugar, alargar a abrangência do fundo contábil, para alcançar toda a educação básica - da creche ao ensino médio. Assim, ampliou a “consciência intergovernamental", já embrionária no Fundef (ABRUCIO, 2010), sobretudo com a definição da nova regra da complementação da União questão mal resolvida no antigo Fundef - em patamar que toma como referência a contribuição dos entes subnacionais ao fundo (no mínimo dez por cento). E, finalmente, criou instância de negociação federativa e regional, a Comissão Intergovernamental de Financiamento Para a Educação Básica de Qualidade (11 membros: MEC e 1 de cada região político-administrativa das esferas estadual e municipal, indicados pelo Conselho Nacional de Secretários de Educação (Consed) e pela União Nacional dos Dirigentes Municipais de Educação (Undime).

Com uma visão sistêmica, procurou proteger o financiamento da educação básica da mera substituição de fontes ${ }^{2}$, com a vedação da utilização da fonte do salário-educação para a complementação da União e também a educação superior- obrigação da União, nos termos do art. 212,1, CF - com a limitação da utilização da fonte de MDE no Fundeb até 30\%.

Embora ainda seja um desafio, o Fundeb também trouxe avanços acerca do aperfeiçoamento das regras referentes aos Conselhos de Acompanhamento e Controle Social (CACS). Elas abarcam impedimentos, autonomia, exercício da presidência, garantias aos conselheiros, instrumentos dos conselhos.

Mas os fundos deixam um legado de avanços em relação à redistribuição, cooperação federativa, inclusão e melhoria da qualidade do sistema, primeiro passo para a melhoria do desempenho de cada aluno - que, para um segundo passo, requer uma política de combate à repetência e à evasão e a melhoria das condições de oferta por meio do atendimento de insumos associados a direitos, cujo caminho mais promissor é na direção do custo aluno qualidade.

\footnotetext{
${ }^{2}$ Isso vem ocorrendo atualmente, com os recursos provenientes dos royalties do petróleo, que estão em ascensão e já financiam parte significativa da complementação da União ao Fundeb. Entretanto, não vêm como acréscimo, porque as antigas fontes são retiradas. Como acentua Tanno, "Em decorrência da Lei de vinculação, o Ministério da Educação tem recebido de forma crescente e consistente recursos dessa natureza". O valor já ultrapassa 11 bilhões de reais.
} 


\section{AS EFICIÊNCIAS E INSUFICIÊNCIAS DO FUNDEB: AVANÇOS, LIMITES E DESAFIOS}

Na lição de José Afonso da Silva (SILVA, 2001, p.337), o princípio da eficiência administrativa, inscrito no art. 37 da Carta Magna, "consiste na organização racional dos meios e recursos humanos, materiais e institucionais para apresentação de serviços públicos de qualidade em condições econômicas e de igualdade de consumidores".

Os fundos contáveis trouxeram maior racionalidade na distribuição dos recursos, na medida em que adotaram um critério educacional - a matrícula - e permitiram significativo efeito redistributivo.

\subsection{EFICIÊNCIA INCLUSIVA}

\subsubsection{AVANÇOS}

A Constituição Federal estabelece a educação como direito de todos. Uma das primeiras dimensões da concretização desse direito é a inclusão. De 4 a 17 anos a educação é obrigatória. Mas, mesmo antes da faixa etária obrigatória, o direito à educação infantil é garantido, havendo a demanda por parte da família. Esta tem sido uma ação do Ministério Público. A jurisprudência é pacífica. O ministro do supremo Tribunal Federal (STF) Celso de Mello, decidiu (ARE 639.337):

A educação infantil, por qualificar-se como direito fundamental de toda criança, não se expõe, em seu processo de concretização, a avaliações meramente discricionárias da Administração Pública, nem se subordina a razões de puro pragmatismo governamental.

$[\ldots]$

Embora inquestionável que resida, primariamente, nos Poderes Legislativo e Executivo, a prerrogativa de formular e executar políticas públicas, revela-se possível, no entanto, ao Poder Judiciário, ainda que em bases excepcionais, determinar, especialmente nas hipóteses de políticas públicas definidas pela própria Constituição, sejam estas implementadas, sempre que os órgãos estatais competentes, por descumprirem os encargos político-jurídicos que sobre eles incidem em caráter mandatório, vierem a comprometer, com a sua omissão, a eficácia e a integridade de direitos sociais e culturais impregnados de estatura constitucional. 
Na faixa de até três anos, embora permaneçam as desigualdades em relação aos recortes mais significativos, até com a ampliação da brecha - quando se considera raça/cor (brancos/negros), localização (urbano/rural) e renda (quartis ou quintis mais pobres e mais ricos), em todos os segmentos menos favorecidos houve inclusão de matrículas, em relação ao período pré-Fundeb, desde o primeiro ano de sua implantação gradativa (2007) e após sua implantação plena, a partir de 2010.

\section{Quadro 1 -Percentual da população de 0 a 3 anos que frequenta a escola/} creche

\begin{tabular}{|l|l|l|l|l|l|}
\hline \multicolumn{1}{|c|}{ Recorte } & \multicolumn{1}{|c|}{$\mathbf{2 0 0 4}$} & $\mathbf{2 0 0 7}$ & $\mathbf{2 0 1 1}$ & $\mathbf{2 0 1 5}$ & $\begin{array}{c}\mathbf{2 0 1 6} \\
\text { (Pnad C) }\end{array}$ \\
\hline Urbano & $19,9 \%$ & $24,2 \%$ & $27,9 \%$ & $33,3 \%$ & $34,6 \%$ \\
\hline Rural & $7,3 \%$ & $10,2 \%$ & $12,7 \%$ & $14,8 \%$ & $17,8 \%$ \\
\hline Meninas & $17,5 \%$ & & & ---- & $31,9 \%$ \\
\hline Meninos & $17,1 \%$ & & & ---- & $31,8 \%$ \\
\hline Negros & $15,4 \%$ & $19,4 \%$ & $23,0 \%$ & $27,1 \%$ & $28,6 \%$ \\
\hline Brancos & $19,1 \%$ & $23,6 \%$ & $27,8 \%$ & $34,0 \%$ & $35,6 \%$ \\
\hline $20 \%$ mais pobres & $11,2 \%$ & $13,7 \%$ & $17,1 \%$ & $20,0 \%$ & $22,3 \%$ \\
\hline $20 \%$ mais ricos & $36,3 \%$ & $41,4 \%$ & $42,6 \%$ & $51,6 \%$ & $48,2 \%$ \\
\hline $\begin{array}{l}\text { Brecha de Acesso entre os } \\
20 \% \text { mais pobres e 20\% } \\
\text { mais ricos }\end{array}$ & 25,1 & 27,7 & 25,5 & 31,6 & 25,9 \\
\hline
\end{tabular}

Obs - para recorte brancos/negros em 2016- uso da Pnad contínua.

Fonte: Dados do Relatório do $2^{\circ}$ ciclo de monitoramento das metas do Plano Nacional de Educação (INEP, 2018).

Entretanto, no caso da faixa de 4 e 5 anos, houve inclusão e diminuiu a brecha no atendimento em todas essas categorias.

Quadro 2 - Percentual da população de 4 a 5 anos de idade que frequentava a escola ou creche

\begin{tabular}{|l|l|l|l|l|l|}
\hline \multicolumn{1}{|c|}{ Recorte } & \multicolumn{1}{|c|}{$\mathbf{2 0 0 4}$} & \multicolumn{1}{|c|}{$\mathbf{2 0 0 7}$} & \multicolumn{1}{|c|}{$\mathbf{2 0 1 1}$} & \multicolumn{1}{|c|}{$\mathbf{2 0 1 5}$} & $\begin{array}{c}\text { 2016 } \\
\text { (Pnad C) }\end{array}$ \\
\hline Urbano & $76,0 \%$ & $81,8 \%$ & $87,3 \%$ & $91,7 \%$ & $92,0 \%$ \\
\hline Rural & $55,3 \%$ & $67,2 \%$ & $77,8 \%$ & $84,6 \%$ & $88,8 \%$ \\
\hline Meninas & $72,6 \%$ & ----- & ----- & --- & $92,0 \%$ \\
\hline Meninos & $71,2 \%$ & ----- & ----- & ---- & $91,1 \%$ \\
\hline Negros & $69,5 \%$ & $76,9 \%$ & $84,9 \%$ & $89,6 \%$ & $90,5 \%$ \\
\hline Brancos & $74,4 \%$ & $81,3 \%$ & $86,6 \%$ & $91,6 \%$ & $92,8 \%$ \\
\hline $20 \%$ mais pobres & $62,9 \%$ & $71,8 \%$ & $80,1 \%$ & $87,9 \%$ & $89,1 \%$ \\
\hline $20 \%$ mais ricos & $91,4 \%$ & $92,3 \%$ & $95,0 \%$ & $96,4 \%$ & $96,4 \%$ \\
\hline
\end{tabular}

Fonte: Dados do Relatório do $2^{\circ}$ ciclo de monitoramento das metas do Plano Nacional de Educação (INEP, 2018).

Também para a faixa de 15 a 17 anos houve avanço conforme se verifica nos quadros 3 e 4 . 
Quadro 3 - Percentual da população de 15 a 17 anos de idade que frequentava o ensino médio ou havia concluído a educação básica - Brasil - 2012-2017

\begin{tabular}{|l|l|l|l|}
\hline \multicolumn{1}{|c|}{ RECORTE } & \multicolumn{1}{|c|}{$\mathbf{2 0 1 2}$} & \multicolumn{1}{c|}{$\mathbf{2 0 1 5}$} & \multicolumn{1}{c|}{$\mathbf{2 0 1 7}$} \\
\hline Urbano & $67,0 \%$ & $71,0 \%$ & $72,2 \%$ \\
\hline Rural & $48,8 \%$ & $54,4 \%$ & $58,9 \%$ \\
\hline Meninas & $70,3 \%$ & $73,3 \%$ & $75,2 \%$ \\
\hline Meninos & $57,6 \%$ & $63,2 \%$ & $65,2 \%$ \\
\hline Negros & $57,3 \%$ & $62,5 \%$ & $65,2 \%$ \\
\hline Brancos & $73,4 \%$ & $76,7 \%$ & $78,1 \%$ \\
\hline
\end{tabular}

Fonte: Dados do Relatório do $2^{\circ}$ ciclo de monitoramento das metas do Plano Nacional de Educação (INEP, 2018)

Assim, nos recortes brancos/negros e urbano rural, verifica-se que houve aumento da matrícula dos negros e da população rural na faixa do ensino médio e alguma diminuição da brecha no atendimento destes alunos em relação aos brancos e à população urbana.

Quadro 4 - Percentual da população de 15 a 17 anos que frequentava o ensino médio ou havia concluído a educação básica, por renda domiciliar per capita Brasil - 2004-2015

\begin{tabular}{|l|l|l|l|l|}
\hline \multicolumn{1}{|c|}{ Recorte } & \multicolumn{1}{c|}{$\mathbf{2 0 0 4}$} & \multicolumn{1}{c|}{$\mathbf{2 0 0 7}$} & \multicolumn{1}{c|}{$\mathbf{2 0 1 1}$} & \multicolumn{1}{c|}{$\mathbf{2 0 1 5}$} \\
\hline $20 \%$ mais pobres & $25,7 \%$ & $34,4 \%$ & $43,9 \%$ & $53,3 \%$ \\
\hline $20 \%$ mais ricos & $83,1 \%$ & $84,2 \%$ & $83,3 \%$ & $88,4 \%$ \\
\hline
\end{tabular}

Fonte: Dados do Relatório do $2^{\circ}$ ciclo de monitoramento das metas do Plano Nacional de Educação (INEP, 2018)

Em dez anos, o quintil mais pobre da população brasileira avançou de, cerca de um quarto, para mais da metade na frequência à escola.

\subsubsection{LIMITES E DESAFIOS}

Se os números mostram um aumento do atendimento do contingente de alunos, em relação à população nas faixas correspondentes às diferentes etapas da educação básica, como aponta Simões, a taxa de atendimento escolar é um critério insuficiente para aferir a "universalização do acesso" (SIMÕES, 2016). Não se pode analisar o acesso de formas dissociada da evasão:

Se por um lado é verdade que $98,5 \%$ das crianças de 6 a 14 anos estão na escola, por outro a trajetória escolar se mostra muito diferente entre os mais ricos e os mais pobres, os últimos sofrendo maior atrito, o que acaba levando à desistência. Apesar dos avanços durante a última década, os $20 \%$ mais pobres ainda guardam diferenças abissais de acesso em relação aos 20\% mais ricos. A probabilidade de um jovem de 16 anos do quintil mais rico concluir o EF na idade recomendada é 1,5 vezes maior que a de um jovem do quintil mais pobre. A probabilidade de um jovem de 19 anos do quintil mais rico chegar ao final do EM na idade recomendada é 2,4 vezes maior que a de um jovem do quintil mais pobre. $\mathrm{O}$ acesso à 
educação básica deve ser integral e universal. Portanto, se nem todos têm acesso a todos os anos escolares, o acesso não está universalizado e, portanto, não está integralizado para um segmento da população. (SIMÕES, 2016, p.38).

Figura 1 - Proporção de jovens (16 anos) que alcançaram os anos escolares do ensino fundamental $-1^{\circ}$ e $5^{\circ}$ quintis de renda per capita (Pnad 2014) - Brasil

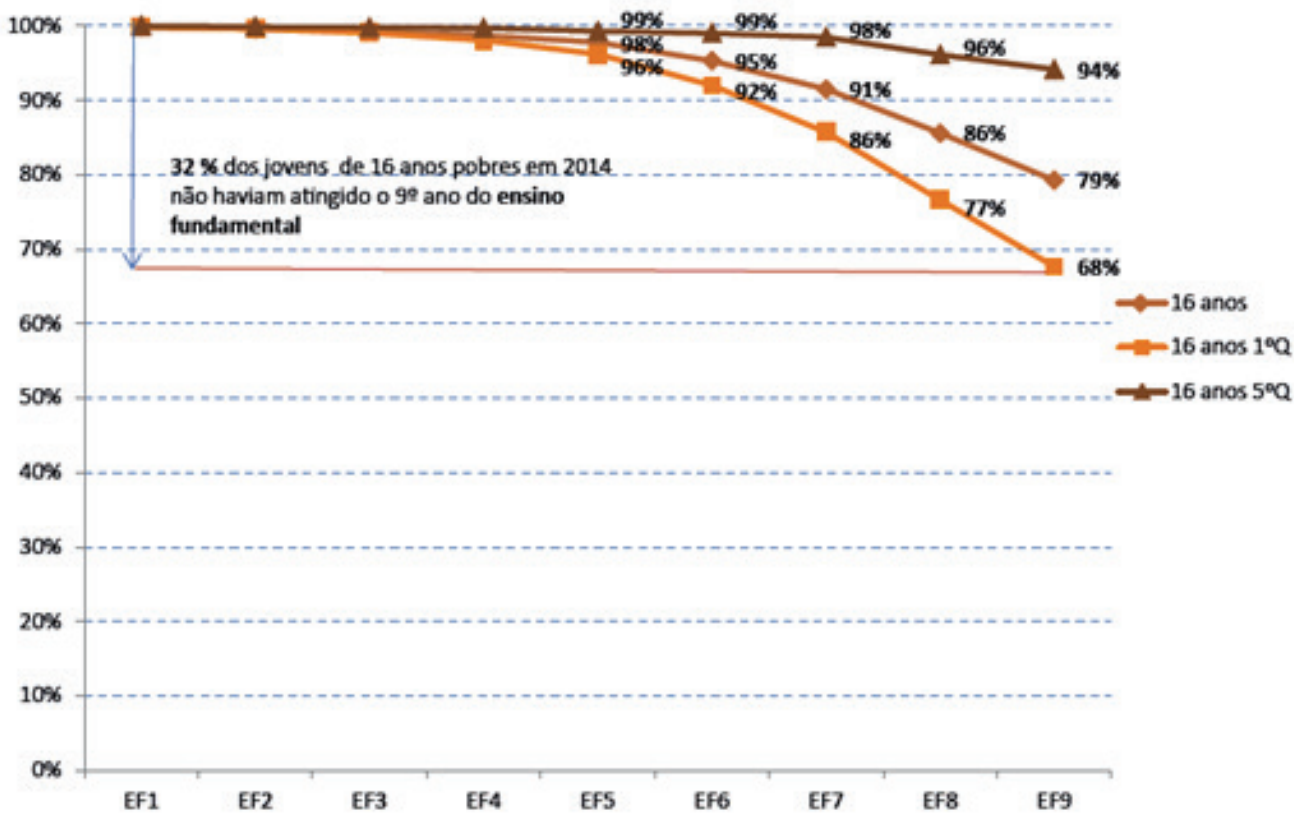

Nota: 1) Somente casos válidos. 2) Pnad reponderada.

Fonte: Simões (2016, p.23).

O autor propõe que se utilize de um novo indicador, que denomina "curvas de acesso", de forma a permitir identificar a desigualdade na trajetória escolar dos educandos.

Assim, se avanços ocorreram, há aspectos que requerem que o novo Fundeb permanente seja mais eficiente para combater a desigualdade - um Fundeb orientado fortemente não só para o acesso, mas para a permanência e regularidade da trajetória escolar, enfim, para a dimensão da equidade que permeie, tanto o acesso como a qualidade.

\subsection{EFICIÊNCIA FEDERATIVA E REDISTRIBUTIVA}

\subsubsection{AVANÇOS}

A política de fundos, desde a implantação do Fundef, gerou maior a consciência intergovernamental (ABRUCIO, 2010, p.64), fato que se ampliou com o Fundeb. 
Em primeiro lugar, as matrículas alcançadas passaram a ser todas aquelas da educação básica, isto é, além do ensino fundamental que era atendido pelo antigo Fundef, também as etapas educação infantil e ensino médio e suas modalidades passaram a ser contempladas.

Houve dois mecanismos importantes para operacionalizar a solidariedade federativa: a complementação da União, no exercício de sua função supletiva, com regra de aporte de no mínimo dez por cento do valor dos fundos e a redistribuição de recursos da cesta Fundeb entre estados e municípios, em cada âmbito estadual, conforme as matrículas ponderadas.

Além disso, criou-se um espaço de negociação federativa, com amplitude regional - a Comissão Intergovernamental de Financiamento para a Educação Básica de Qualidade composta por um representante de cada uma das regiões político-administrativas brasileiras, tanto no nível estadual como na esfera municipal, indicados, respectivamente, por Consed e Undime.

Como política que lida de forma sistêmica com a educação básica o Fundeb teve efeito indutor: a Emenda Constitucional n. ${ }^{\circ}$ 53/2009, que aprovou o Fundeb:

» promoveu ampliação do alcance do salário-educação, constitucionalizando, ainda, sua distribuição segundo as matrículas ${ }^{3}$ - o que ampliou a colaboração federativa ${ }^{4}$;

» acrescentou um "s" no parágrafo único do art. 23 da Constituição Federal, de forma a abrir caminho para que se elaborasse uma lei complementar referente à cooperação federativa - que não é outra senão a lei que trate do sistema nacional de educação ${ }^{5}$.

Os recursos da complementação da União foram essenciais para a diminuição das desigualdades entre os valores por aluno dos vinte e sete âmbitos estaduais. Entre 2007 e 2014, a complementação da União, cresceu, em termos reais, 289\%. Nesse período, estudo do Inep (OLIVEIRA et alli, 2015 ) indica que:

» antes da complementação da União, em 2007, a distância entre o grupo de âmbitos estaduais que recebiam a complementação da União e que não recebiam (por apresentar VAA acima do mínimo nacional) que seria de 87,7\%.

\footnotetext{
${ }^{3}$ Esse critério foi adotado desde a Lei n. ${ }^{\circ}$ 9.766/1998, ainda quando a distribuição era apenas para o ensino fundamental.

${ }^{4}$ Esse caminho indicado pela $E C$ n. ${ }^{\circ} 53$ seria seguido pela $E C$ n. ${ }^{\circ} 59$, que ampliou os programas suplementares para toda a educação básica. A Exposição de Motivos n. 005 MEC/MPOG, que acompanhou a Medida Provisória n. ${ }^{\circ}$ 455/2009, convertida na Lei n. ${ }^{\circ} 11.947$, de 2009, assinalava: "4. Nesse sentido, as experiências consolidadas representadas pelo Programa Nacional de Apoio ao Transporte Escolar - PNATE, pelo Programa Nacional de Alimentação Escolar - PNAE e pelo Programa Dinheiro Direto na Escola - PDDE, justificam sua ampliação para toda a educação básica a partir de 2009, o que significa apoiar não apenas o ensino fundamental, mas também o ensino médio e a educação infantil".

${ }^{5}$ Na 55a legislatura tramitaram os PLPsnºs 15/2011, 413/2014 e 448/2017, respectivamente dos Deputados Felipe, Ságuas Moraes e Giuseppe Vecci. Ao fim da legislatura as proposições foram, regimentalmente arquivadas e, como os propositores não retornaram à Câmara, não houve desarquivamento. Na 56ª legislatura, tramita o PLP nº 25/2019, cuja autora é a Deputada Profa Dorinha Seabra Rezende.
} 
Após a complementação a distância, considerado o VAA médio das séries iniciais do ensino fundamental urbano (que corresponde ao valor de referência, fator 1 das ponderações), caiu para 57,7\%;

» houve encurtamento da distância continuamente. Assim, em 2014, sem a complementação da União, a distância entre esses grupos, que seria de 67,1\% caiu para $20,8 \%$.

Conforme assinala Araujo (2012), ainda para analisar o impacto distributivo do antigo Fundef,

Vazquez (2007) construiu uma tabela de valores médios aluno/ano, por unidades federativas e regiões. Adotou o valor médio nacional igual a 100, a fim de verificar se os valores aplicados nas unidades da federação aproximaram-se ou distanciaram-se da média. Com os dados, ele construiu três indicadores de desigualdade interestaduais: a) razão entre o valor mínimo e o médio; b) razão entre o valor máximo e o mínimo; e c) razão entre o desvio-padrão e o valor médio. O último indicador representa uma medida de dispersão relativa, exprimindo a variabilidade em relação à média, ou seja, quanto maior o coeficiente, maior a desigualdade (ARAUJO, 2012, p.53).

Ao atualizar os dados até 2012, Araujo (2016) pôde, ao verificar esse conjunto de indicadores 6

inferir que a implantação do Fundeb representou uma sensível diminuição das desigualdades entre unidades subnacionais no que diz respeito à repartição dos recursos vinculados a política de fundos, nunca sendo demais relembrar que o fundo abarca parte dos recursos disponíveis e não incidindo em outros componentes desta desigualdade (ARAUJO, 2016, p.142).

Estudo do Inep (PERESE et all, 2015) analisou sete faixas de "Resultado Líquido das Transferências do Fundeb" (RL), que expressam intervalos financeiros de decréscimo e acréscimo de receitas ocasionadas pela distribuição intraestadual de recursos dos Fundos no âmbito de cada Estado. Os resultados indicaram que:

A característica principal da redistribuição intraestadual é que a maioria dos governos municipais brasileiros (59,7\%) teve acréscimo de recursos com o Fundeb em, pelo menos, 10\%: 32,8\% tiveram um acréscimo entre $10 \%$, e $100 \%$ e $26,9 \%$ dos governos municipais tiveram RL acima de 100\%. As análises de correlação revelaram que há uma tendência geral de que quanto maior o RL no Fundeb, pior a situação socioeconômica e educacional dos municípios.

\footnotetext{
${ }^{6}$ Araujo indicou que, em 2012, o valor mínimo equivalia a 85\% do valor médio, em contraste com o último valor do antigo Fundef em 2006, de 56,3\%; a distância entre os valores mínimo e máximo foi de 2,6 vezes enquanto no Fundef/2006 era de 4,32 e o coeficiente de variação, que era de 0,34 no Fundef/2006 foi para 0,16 em 2012 (ARAUJO, 2016).
} 
Assim, mesmo ao se olhar apenas para os recursos da cesta Fundeb houve avanço importante.

\subsubsection{LIMITES E DESAFIOS}

A situação que gerou a advertência de Araújo teria já sido identificada pelo grupo de trabalho que, no âmbito do MEC, em 2015, discutiu critérios para a implementação do custo aluno qualidade - GT CAQ (2015): o valor total disponível por aluno, consideradas todas as receitas vinculadas à educação, para cada rede ou sistema de ensino permanece desigual.

E audiência pública da Comissão Especial do Fundeb, realizada na 55a legislatura, em 07/03/2017, Araújo (2016) declarou:

O FUNDEB conseguiu diminuir essa distância dentro dos recursos que estão no fundo. Mas essa distância real é maior quando pegamos todos os recursos. Dentro dos $20 \%$ que são retirados para criar o fundo, ele foi eficiente. Ele é muito mais justo do que o FUNDEF. Mas digamos que isso é uma parte do olhar. Uma outra forma de se verificar melhor é utilizar o Coeficiente de Gini para averiguar se os Municípios brasileiros, todos eles, independentemente de serem paulistas ou maranhenses, se tornaram menos desiguais. O FUNDEB melhorou, mas não melhorou tanto. No Coeficiente de Gini, nós saímos de 0,24 para 0,21. Houve uma melhora, mas, como os recursos próprios fazem a diferença, acontecem picos de desigualdade que continuam influenciando, como é o fato de três ou quatro Estados brasileiros terem uma arrecadação muito grande. Com isso, os seus Municípios sobem, mantendo a desigualdade. Como a complementação da União cresceu e está muito melhor do que foi no FUNDEF, mas está no patamar de 10\%, o que dá 0,21\% do PIB, essa complementação não foi suficiente para reduzir a desigualdade de forma significativa. Quanto maior a complementação da União, menor é o coeficiente de desigualdade entre os Municípios. (BRASIL, 2017).

Para enfrentar essa questão, o substitutivo da proposta do novo Fundeb propõe a adoção do critério do valor aluno ano total (VAAT), que considera todos os recursos vinculados para, a partir daí, traçar a estratégia de diminuição das desigualdades. 


\subsection{EFICIÊNCIA DE RESULTADOS}

\subsubsection{CONTEXTO}

A partir da redação dada pela EC n. ${ }^{\circ}$ 59/2009 ao art. 212, §3º da Constituição Federal, o financiamento do ensino obrigatório (4 a 17 anos) foi reconhecido como indissociável destes três objetivos: universalização, equidade e qualidade.

Enquanto para alguns autores, as avaliações podem ser orientadas por insumos e processos ou, alternativamente, por resultados, vistos como desempenho dos educandos em testes padronizados (FERNANDES; GREMAUD, 2009, 2019), pode-se entender, também que há uma indissociabilidade desses elementos. A Qualidade da Educação pode ser examinada a partir de uma abordagem que tenha por base o "paradigma relação insumos-processos-resultados" (DOURADO et alli, 2007). Para Mello e Costa, "Uma análise que deixe de lado qualquer destes elementos será fatalmente falha e incompleta" (MELLO; COSTA, 1993, p.12).

A abordagem a partir do custo aluno qualidade procura enfatizar as condições para que seja oferecida a educação de qualidade.

Embora esteja longe de um desfecho decisivo, o debate em torno da avaliação teve um marco no enunciado da meta 7 do Plano Nacional de Educação (PNE), que - a despeito do que indica a estratégia 7.21, que remete à avaliação por meio de insumos - consagra, a avaliação por resultados, medida por testes padronizados.

Há uma inversão no PNE: as Metas 7 e 20 deveriam ser, também, importantes estratégias para alcançar o disposto no artigo 11 da Lei n. ${ }^{\circ} 13005$, de 2014, sobre o Sistema Nacional de Avaliação da Educação Básica (SINAEB), ao invés de ter como referência a tabela do Ideb. Além disso, ambas as metas, seriam referências para a estratégia 20.7, que trata a adoção do Custo Aluno Qualidade (CAQ). Fernandes e Gremaud (2019) indicam algumas das críticas que fazem os céticos - como eu - à abordagem limitada a testes padronizados: utilização apenas de provas de matemática e português e a não consideração de aspectos não-cognitivos. Destacam, ainda, os potenciais riscos de distorção dos incentivos, com o estreitamento do currículo e da prática do "gaming", inclusive com a exclusão dos alunos de baixa proficiência?.

${ }^{7}$ Este fenômeno foi retratado na cultura pop, em episódio do desenho animado americano, Os Simpsons, no qual o adolescente Bart e seus amigos com pouco aproveitamento escolar, ganham como "prêmio' um dia fora da escola - o dia da realização do exame. 
O Índice de Desenvolvimento da Educação Básica (ldeb), indicador transformado em meta do PNE ao menos minimiza o efeito de adoção apenas dos testes padronizados, já que agrega uma medida de desempenho (nível médio de proficiência na Prova Brasil) e outra de rendimento (valor médio das taxas de aprovação, de forma a refletir o fluxo escolar). Ainda assim, Soares e Xavier (2013), ao analisar as opções metodológicas feitas na construção do Ideb, ponderam que há alguns problemas:

» só alunos presentes ao teste são considerados;

» proficiência em Matemática tem mais peso do que proficiência em Leitura: "...; o indicador de aprendizado do Ideb assume, equivocadamente, que os alunos brasileiros de ensino fundamental sabem mais Matemática do que Leitura" (SOARES; XAVIER, 2013, p.909);

» assume substituições questionáveis entre os diferentes componentes: o bom desempenho de um aluno compensa o mau desempenho de outro;

» a escala do Ideb varia de 0 a 10 e induz o leigo a usar a metáfora da nota escolar para analisar o Ideb: “Um Ideb em torno de 7 - um excelente resultado é, por outro lado, uma nota escolar mediana” (SOARES; XAVIER, 2013, p.917).

» naturaliza baixos desempenhos de muitos alunos: mesmo o "Ideb igual a 6, a meta nacional, é compatível com um grande número de alunos com desempenhos medíocres" (SOARES; XAVIER, 2013, p.917);

» o Ideb é muito correlacionado com o nível socioeconômico da escola.

Os autores relacionam, ainda outras críticas que surgiram no debate desse tema:

» não consideração de aspectos que têm impacto sobre a qualidade, como a valorização dos profissionais e a infraestrutura (Daniel Cara);

» indicação do problema, mas não do que deve ser melhorado (João Batista de Oliveira);

» indução a hierarquizações como forma de análise da realidade educacional.

O art. 11 do PNE prevê o sistema nacional de avaliação da educação básica, que é mais adequado para verificar a qualidade em todas suas dimensões - a qualidade do sistema é, como apontado, indissociável de sua relação expressa no art. 212, §3 , CF: não há qualidade de sistema que não garanta a inclusão e a equidade. A inclusão de mais educandos, impulsionada a partir da Constituição Cidadã que recém completou trinta anos, é um dado de qualidade do sistema e não se pode a ela imputar a causa de "perda de qualidade", a partir de avaliações que desconsiderem essa situação (BEISIEGEL, 2006). A inclusão de educandos com baixa renda - que pode ter um reflexo imediato de "queda” nos índices de aproveitamento. São apontadas as diferenças de desempenho segundo os quintis de renda: se um sistema aprimora sua política 
de busca ativa e traz mais alunos que estavam fora da escola - ou os recebe, se for o caso de município que atraia fluxo migratório - provavelmente os de baixa renda, eventualmente as "notas do Ideb" cairão. E, no entanto, a ação foi de melhoria da qualidade do sistema.

É necessário, antes de indicadores de qualidade, cuidar da qualidade dos indicadores. O Ideb tem as fragilidades apontadas como indicador, embora possa ser utilizado como um bom "marcador": se há diminuição da diferença de Ideb realmente pode ser considerada evidência de diminuição das desigualdades. Mas, ao contrário, a utilização isolada do Ideb, baseada na média, pode esconder um aumento da desigualdade e, portanto, uma piora da qualidade do sistema.

Circulam propostas de destinação de parte dos recursos da complementação da União ao Fundeb segundo critérios de desempenho. Considero isso uma ideia fora do lugar, um grave erro. Aprovada proposta dessa natureza, qual a sequência? Qual o critério para avaliar a evolução de desempenho? O Ideb - que além de todas as fragilidades apontadas, não capta quem está fora da escola e tampouco a educação infantil? Um sistema que renuncia à busca ativa tem qualidade?

Há um grande risco de subjetivismos, ressurgimento dos balcões e potencial de acirramento de conflitos federativos se trazida para dentro do Fundeb a fixação de condicionalidades referente a resultados para recebimento de parte de recursos.

Isto não significa desconsiderar o tema no conjunto do financiamento - que não se limita ao Fundeb. O Fundeb representa 63\% dos recursos da educação básica. Há muito espaço para testar experiências que busquem o melhor desempenho "fora do Fundeb", dentro de uma visão sistêmica do financiamen-

to e com a vantagem adicional de permitir maior coordenação dos estados em seu território, a partir de pactuações federativas segundo sua realidade, alavancando o regime de colaboração com os municípios: a utilização da cota municipal do ICMS. Uma boa experiência é a do estado do Ceará, em relação à distribuição da cota municipal do ICMS. No âmbito da PEC 15 de 2015, há proposta do Deputado Bacelar nessa direção.

A vocação do Fundeb é o apoio à universalização e permanência, com aumento da jornada. Misturar isso com condicionalidades apoiadas em testes padronizados é uma ideia fora do lugar. 


\subsubsection{AVANÇOS}

Feitas todas essas ressalvas, estudo de pesquisadores do IPEA (ARAUJO et. ali, 2019) indica que nos anos inicias o Brasil tem alcançado e superado as metas propostas para o Ideb. Um desses pesquisadores (Herton Araujo) ao fazer apresentação no Ministério da Educação, em 10 de maio de 2019, menciona o que considera a revolução nos anos iniciais, segundo os gráficos 1 e 2 .

\section{A Revolução nos Anos Iniciais ipea}

\section{Municípios ordenados pelos IDEB's Anos Iniciais de 2007}

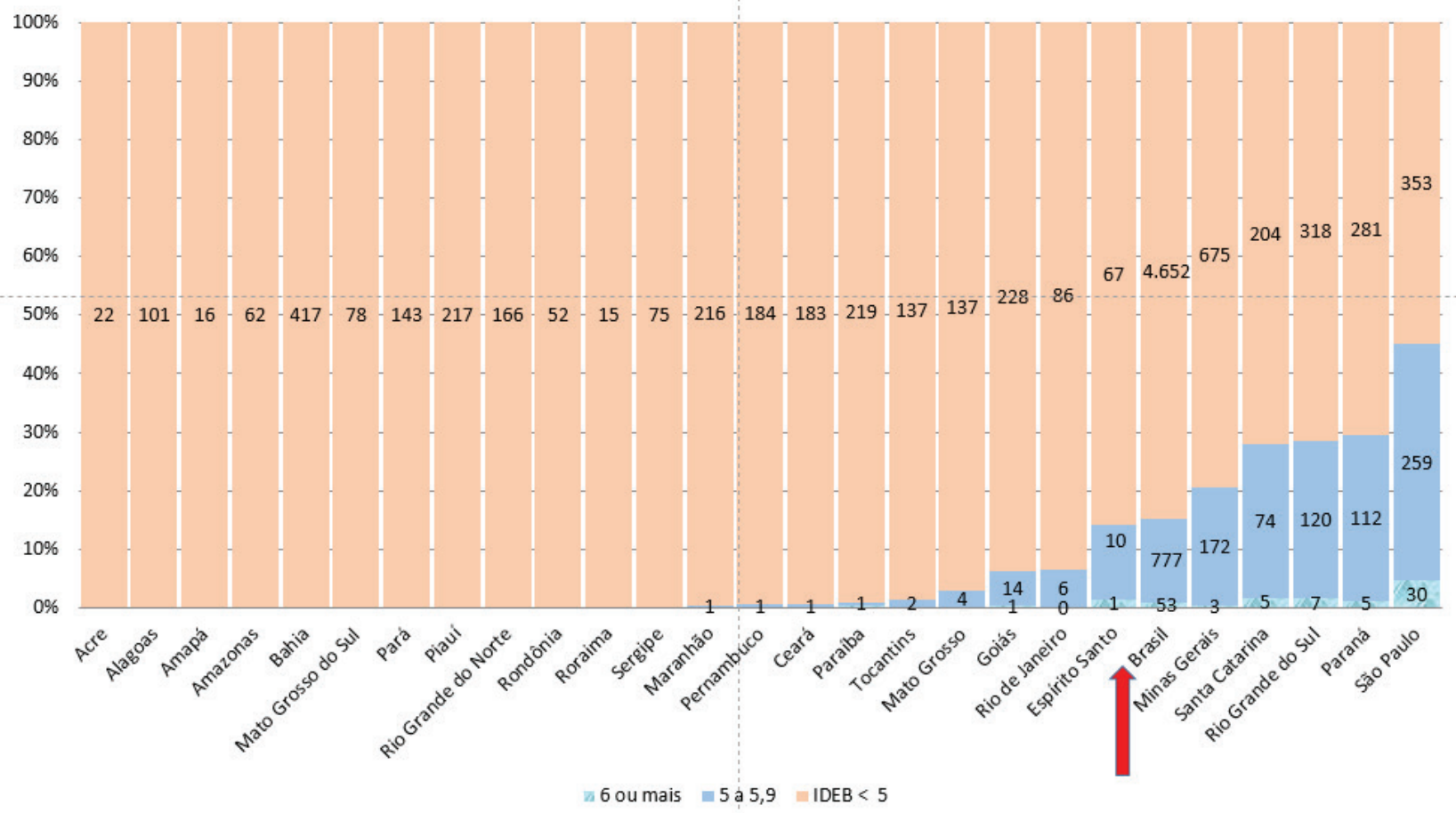




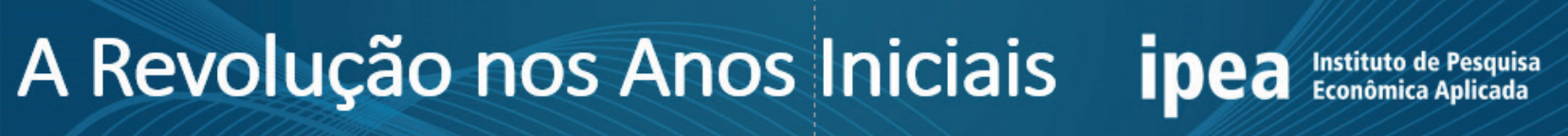

\section{Municípios ordenados pelos IDEB's Anos Iniciais de 2017}

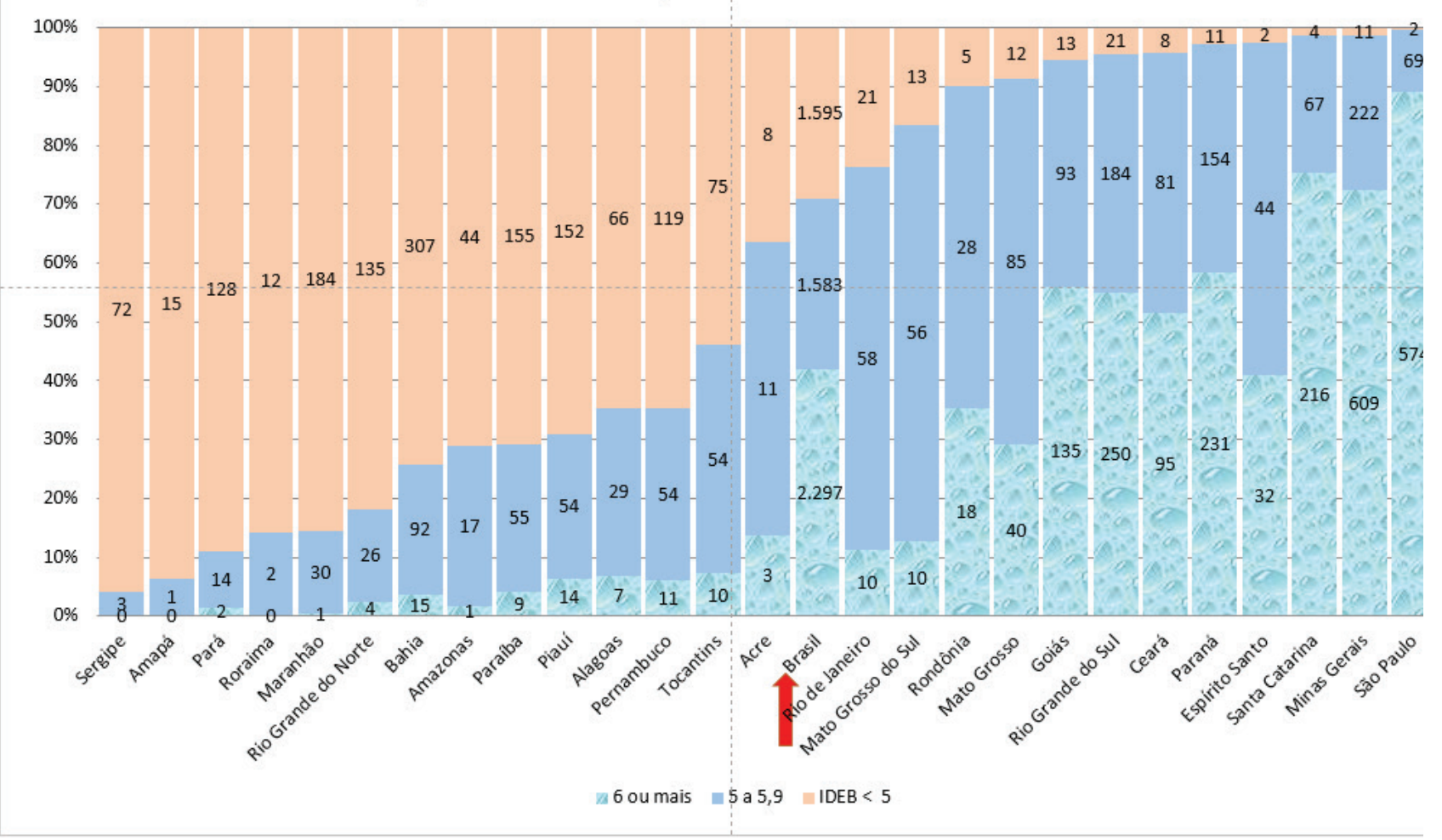

Fonte: Herton Araujo (Ipea, 2019).

\subsubsection{LIMITES E DESAFIOS}

É preciso, ainda, desmistificar a ideia de que não são necessários recursos para melhorar a qualidade. Recursos são uma condição necessária, mas não suficiente. Mesmo se tomado o Ideb como referência, há dados que apontam essa relação.

Trabalho apresentado ao XXXV encontro da Associação Nacional de Pós-Graduação e Pesquisa em Administração (Anpad) concluiu-se que:

A correlação entre a média do gasto do ano do exame e o IDEB mostrou-se entre de baixa a média intensidade na maioria das categorias de municípios nas três versões do exame. Exceção são os municípios com mais de 1 milhão de habitantes para os quais a correlação é de alta. Assim, aceita-se de forma moderada a hipótese de que maior gasto médio por aluno matriculado no ensino fundamental de escolas municipais resulta em melhor nota no IDEB no ensino fundamental dos municípios 
brasileiros. Os dados indicam também que os investimentos contínuos em educação são capazes de refletir melhoras interessantes na qualidade da educação. Pela análise dos dados e das correlações, conforme os gastos médios foram acumulados no tempo, primeiro pelo período de anos que o aluno ficou matriculado, segundo pela série temporal de dados disponível até a aplicação do exame, os coeficientes mostraram melhora significativa na correlação entre a média do gasto por aluno e o IDEB, tanto para os anos iniciais ou quanto os anos finais. Podemos aceitar, então, a hipótese de que maior gasto médio por aluno no ensino fundamental dos municípios brasileiros consistente em certo período resulta em melhor nota no IDEB no ensino fundamental dos municípios brasileiros. (CROZATTI, 2011).

Comunicação mais recente ao Congresso de Contabilidade de 2015, promovido pela UFSC e Universidade de Valencia, Silva et alli (2015, p. 10) apontaram: "[...] mantendo-se constante as demais variáveis que influem o IDEB e que não foram contempladas no presente estudo, um aumento de 10\% nas despesas públicas em educação, ocasiona uma melhora de 1,9\% no IDEB".

\section{A IDENTIDADE CONSTITUCIONAL}

Todos os objetivos consagrados na Constituição, para garantir o direito à educação desde o acesso com permanência, equidade e qualidade, numa ambiente solidariedade federativa e de regime de colaboração pressupõe um bem estruturado sistema de financiamento.

A base desse sistema foi a vinculação de recursos à manutenção e desenvolvimento do ensino, desenho que foi sendo aprimorado com a emendas constitucionais n. ${ }^{\circ}$ s 14, 53 e 59, que consolidaram a política de fundos e promoveram uma expansão qualificada da educação, de forma a ampliar direitos e mecanismos de sua garantia (MARTINS, 2019).

Em todos os momentos em que caiu a vinculação houve diminuição de investimento na educação. 
Figura X - \% do PIB despendido em educação

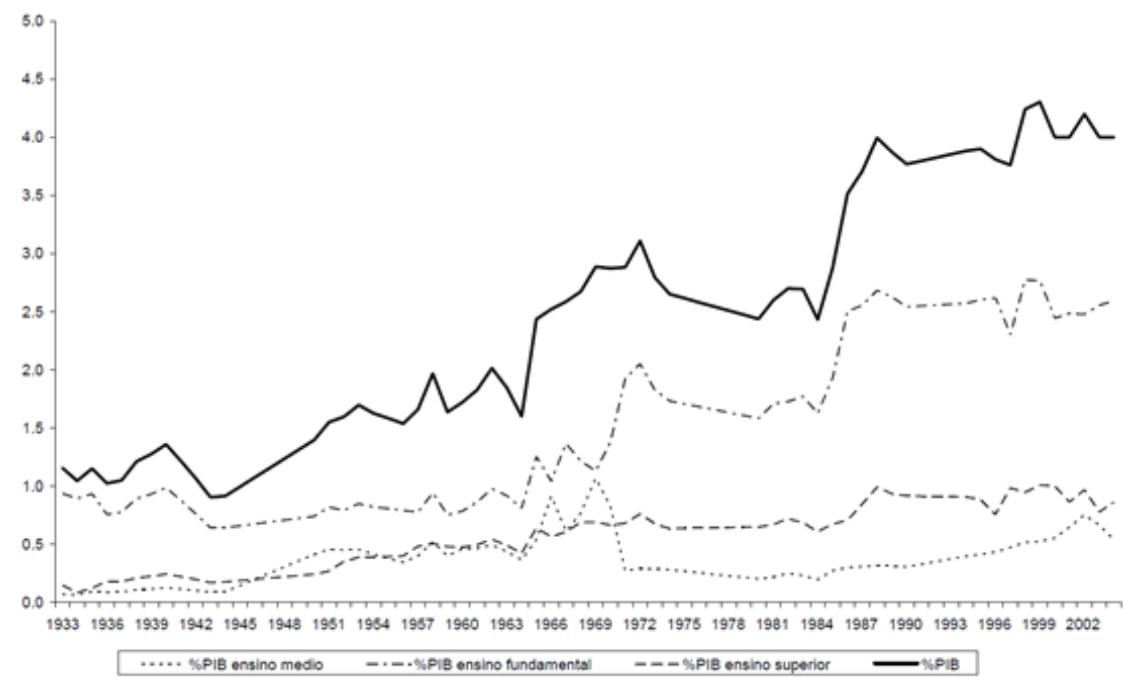

Fonte: Maduro Junior (2007, p.25)

A educação foi recuperando alguns dos pilares sugeridos já no manifesto dos pioneiros da educação nova e em suas propostas para a Carta de 1934: a adoção da doutrina federativa, e a vinculação de recursos à educação, organizada por meio de fundos e o reconhecimento da educação como função essencialmente pública, com a opção pelo ensino público.

José Afonso da Silva (2001) afirma a preferência constitucional pelo ensino público e assinala:

As normas têm, ainda, o significado jurídico de elevar a educação à categoria de serviço público essencial que ao Poder Público impende possibilitar a todos. Daía preferência constitucional pelo ensino público, pelo que a iniciativa privada, nesse campo, embora livre, é, no entanto, meramente secundária e condicionada (arts. 209 e 213). (SILVA, 2001, p.316).

E, adiante:

[...]. Esses recursos, como qualquer outro recurso público, serão destinados à escola pública. Faculta-se, por exceção, dirigir recursos públicos a escolas comunitárias, confessionais ou filantrópicas, inclusive por meio de bolsas de estudos a quem demonstrar insuficiência de recursos, quando houver falta de vagas e cursos regulares na rede pública na localidade da residência do educando. (SILVA, 2001, p.816). 
Em seu "Comentário contextual à Constituição" (2009) o jurista afirma:

O texto é simples. Confirma a preferência pelo ensino público, tanto que define que os recursos públicos devem ser destinados às escolas públicas. Mesmo quando abre exceções, o faz em relação a entidades que têm um sentido social - e a Constituição, assim, as aproxima dos objetivos da escola pública -, que são as escolas comunitárias, confessionais ou filantrópicas, como tais definidas em lei. Ainda assim, o dispositivo só admite a ajuda pública nas condições enumeradas - quais sejam: comprovarem finalidade não-lucrativa e a aplicação de seus excedentes financeiros em educação; assegurarem a destinação de seu patrimônio a outra escola da mesma natureza ou ao Poder Público, no caso de encerramento de suas atividades. (SILVA, 2009, p.801).

Clara, pois, está o que se denomina da identidade constitucional, no caso das normas constitucionais referentes à Educação: a preferência pelo ensino público, para o qual são destinados, como regra, os recursos públicos e o estabelecimento da vinculação constitucional, reconhecida expressamente a partir da Emenda n. ${ }^{14}$, como princípio sensível, cujo desrespeito enseja a intervenção federal.

Não há dúvida sobre o que dispõe a Carta Magna - a destinação de recursos públicos é para as escolas públicas e, excepcionalmente, sob condições e restrita a alguns tipos de instituições, pode ser direcionada para algumas instituições privadas.

Qualquer emenda que vulnere essa identidade padece do vício de inconstitucionalidade material.

A ministra Carmen Lúcia Rocha Antunes (1993), ao discorrer sobre os fundamentos dos limites ao poder reformador, afirma (grifos nossos):

Faz-se imprescindível a limitação do exercício do poder reformador da Constituição, porque sem essa definição nenhum sistema jurídico se daria ao cumprimento, ficando o direito e, principalmente, a própria sociedade ao sabor de injunções momentâneas, emocionais, precárias.

[...] De outra parte, se o poder constituinte originário não impusesse limites ao desempenho do poder constituinte derivado de reforma estaria proclamando o seu suicídio, pois estaria a aceitar que a sua obra fragilizasse e fosse substituída e não apenas modificadas, eis que sem limites, a sua transformação em essência deitaria por terra tudo quanto identificasse o sistema por ele criado.

[...] a perda da identidade constitucional, a transformação da ideia de Direito prevalente em determinado sistema, para serem legítimos, precisam ser respaldados diretamente no povo, em cujo seio o poder constituinte tem moradia certa. (ANTUNES, 1993, p.167,168 e 170). 
Reconhece a jurista, acompanhando grande parte da doutrina, a existências de "limites materiais implícitos ou imanentes, dotados de tanta força vinculante e proibitiva" quanto as contidas nas cláusulas pétreas expressamente previstas. E aduz:

Os limites materiais implícitos ou imanentes são considerados os de mais difícil desate na doutrina e na experiência constitucional contemporânea: difícil porque não estando articulados tendem a ser menosprezados ou desconsiderados pelas maiorias parlamentares que pretendem arvorar-se em grandes reformadores e que, nesta atuação, decidem exorbitar os limites ou não conviver com eles, tanto mais quanto não se possam demonstrá-los articuladamente; importantes porque não poucas vezes, substitui-se uma Constituição por outra, sem se permitir o debate sobre a legitimidade e a constitucionalidade da reforma processada, pela modificação ou substituição de princípios e regras que, conquanto não toquem literalmente os limites materiais expressos, deitam-nos por terra a desfazer todo o arca-

bouço e a identidade constitucional. (ANTUNES, 1993, p.177).

Esses limites materiais "implícitos”, reclamam proteção jurídica reforçada na medida em que a "supressão de tais matérias implicaria, por via oblíqua, no esvaziamento da identidade constitucional” (BEDÊ, 2006, p.103).

No campo educacional, a preferência pelo ensino público e a vinculação constitucional integram o núcleo da identidade constitucional.

Mas, de volta ao que está expresso, e não implícito na Carta Magna, no art. 213, é imperativamente estabelecida a regra ("serão destinados”) - destinação de recursos públicos para escolas públicas - e indicada a exceção, facultativa ("podendo") e condicionada (incisos I e II): eventual destinação para escolas comunitárias, confessionais ou filantrópicas. Para escolas que não tenham essa natureza, sequer há possibilidade de destinação.

A legislação do Fundeb segue a diretriz constitucional, de destinação, como regra, para as instituições públicas e admite as exceções (art. $8^{\circ}, \S 1^{\circ}$, I, II e III, IV e V Lei n. $\left.{ }^{\circ} 11.494 / 2007\right)$ abrigadas no art. 213 da Constituição e, nos termos do art. 209, incisos I e II, estabelece condições de igualdade de acesso e permanência e gratuidade ( $\left(2^{\circ}\right.$, inciso I) e pedagógicas $\left(\S 2^{\circ}\right.$, inciso IV-atender a padrões mínimos de qualidade definidos pelo órgão normativo do sistema de ensino, inclusive, obrigatoriamente, ter aprovados seus projetos pedagógicos). Em se tratando de exceção o universo beneficiado abrange a educação infantil, especial e educação do campo oferecida pelas instituições privadas dessa natureza. 
A lei mantém, ainda, a preferência pela escola pública e a destinação à Manutenção e Desenvolvimento do Ensino (MDE):

Art. $8^{\circ}$.

$\S 5^{\circ}$ Eventuais diferenças do valor anual por aluno entre as instituições públicas da etapa e da modalidade referidas neste artigo e as instituições a que se refere 0 § 10 deste artigo serão aplicadas na criação de infraestrutura da rede escolar pública.

$\S 6^{\circ}$ Os recursos destinados às instituições de que tratam os $\S \S 1^{\circ}, 3^{\circ}$ e $4^{\circ}$ deste artigo somente poderão ser destinados às categorias de despesa previstas no art. $\mathbf{7 0}$ da Lei $\mathbf{n} .^{\circ} \mathbf{9 . 3 9 4}$, de 20 de dezembro de 1996.

A partir dos princípios estabelecidos pelo constituinte foi tecida a identidade constitucional, que dá coerência sistêmica às políticas educacionais e deve ser observada pelas normas constitucionais e infraconstitucionais.

\section{DESVIOS DE RUMOS}

As ameaças ao rumo do Fundeb são exatamente as que desfiguram a identidade constitucional na área da educação. Em primeiro lugar a desvinculação, que "Desorganiza os meios de financiamento e a reserva de recursos para o exercício da função supletiva. Destrói a política de cooperação, o regime de colaboração" (ANPED, 2019). É a vinculação possibilita que os entes federados realizem as suas tarefas próprias e exerçam as funções supletiva e redistributiva (art. $30, \mathrm{VI}$ e art. $211, \S \S 1^{\circ}$ e $3^{\circ}, \mathrm{CF}$ ).

E, sem vinculação não há subvinculação, não há Fundeb, o que fere toda a construção de colaboração federativa que esse mecanismo trouxe. A desvinculação é uma proposta essencialmente antifederativa e, ao longo da história verificou-se que sempre que suprimida a vinculação, caem os investimentos em educação.

É a identidade constitucional a vacina contra condutas predatórias e ideias fora de lugar ${ }^{8}$.

\footnotetext{
${ }^{8}$ No processo de discussão do antigo Fundef, surgiu uma típica ideia fora de lugar. Hordas de grupos de advocacy e juristas da área de esporte pretendiam que os recursos do Fundef cobrissem despesas que, sem dúvida importantes, deveriam ter seus próprios instrumentos, inexistentes à época, mas depois criados com as leis de incentivo ao esporte e a chamada Lei Agnelo Piva (Lei n. ${ }^{10.264 / 2001)}$, que destina recursos às confederações desportivas que atuam junto às escolas e universidades para desenvolvimento do desporto escolar e universitário.
} 


\section{RUMO AO FUNDEB PERMANENTE}

A discussão iniciada na Câmara dos Deputados, a partir da apresentação da proposta de emenda à Constituição (PEC) n. ${ }^{\circ}$ 15, de 2015 vem traçando rumos importantes para o Fundeb.

Em primeiro lugar, já o texto original da deputada Raquel Muniz propõe o Fundeb como um instrumento permanente. A proposta traz também importantes princípios (planejamento na ordem social e proibição do retrocesso), aos quais se somam outros propostos pela relatora, Deputada Professora Dorinha Seabra Rezende (responsabilidade solidária e o custo aluno qualidade, como referência para o padrão mínimo definido nacionalmente, ação redistributiva entre as escolas de cada rede).

Foram realizadas, na comissão especial da Câmara dos Deputados, quase trinta audiências públicas na 55ª legislatura e mais dez na 56ª

A esse esforço soma-se o debate no Senado Federal e um importante diálogo entre a relatora da Câmara e o senador Flávio Arns, relator da PEC 65 do Senado.

Duas ideias orientam os novos rumos do Fundeb permanente: a solidariedade federativa e a equidade.

Dessa forma, a proposta contida nas três PECs - as PECs n. ${ }^{\circ}$ s 33/2019 e 65/2019, em tramitação no Senado Federal e na PEC 15/2015, discutida na Câmara é a majoração da contribuição da União pela via da complementação em prazo gradual.

Quadro 5 - Complementação da União -propostas das PECS

\begin{tabular}{|l|l|l|l|}
\hline \multicolumn{1}{|c|}{ Proposta } & $\begin{array}{l}\text { Minuta de substitutivo } \\
\mathbf{1 5 / 2 0 1 5}\end{array}$ & \multicolumn{1}{|c|}{$\mathbf{3 3 / 2 0 1 9}$} & \multicolumn{1}{|c|}{$\mathbf{6 5 / 2 0 1 9}$} \\
\hline $\begin{array}{l}\text { Patamar } \\
\text { inicial }\end{array}$ & $15 \%$ & $12 \%$ & $20 \%$ \\
\hline Patamar final & $30 \%$ & $30 \%$ & $40 \%$ \\
\hline Gradualismo & $\begin{array}{l}\text { A partir de 15\%, com } \\
\text { acréscimo de um inteiro } \\
\text { e cinco décimos pontos } \\
\text { percentuais a cada ano }\end{array}$ & $\begin{array}{l}12 \% \text { no primeiro } \\
\text { ano, 15\% no } \\
\text { segundo e 30\% a } \\
\text { partir do terceiro }\end{array}$ & $\begin{array}{l}\text { A partir de 20\% } \\
\text { aumentando } \\
\text { pentos } \\
\text { percentuais a } \\
\text { cada ano }\end{array}$ \\
\hline
\end{tabular}

Mas, se é necessária uma maior participação do ente federativo que mais arrecada, não é razoável que seus recursos sejam distribuídos sem que se leve em conta, nos níveis subnacionais, algumas distorções já identificadas pelo GT CAQ (2015), isto é, municípios ditos ricos em estados pobres enquanto outros pobres em estados mais desenvolvidos poderiam receber. Daí a ideia defendida pela relatora da Câmara, de distribuição da complementação por 
redes. Para operacionalizar essa diretriz, foi elaborado pelo consultor de orçamento e fiscalização financeira da Câmara dos Deputados, Cláudio Tanno, o Estudo Técnico n. 24/2017-CONOF/CD (Outubro/2017), em que propôs a adoção como critério para distribuição dos recursos da complementação, do que denominou valor aluno ano total (VAAT), que considera todas as fontes vinculadas à MDE, mesmo as que não estão na cesta-Fundeb (ISS, ITBI, IPTU), quando se calcular a complementação. Essa foi a principal inovação proposta pela relatora da PEC n 15/2015, Deputada Profa Dorinha Seabra Rezende, em suas duas minutas de substitutivo.

Numa primeira versão, apresentada na 55a legislatura, eram previstas duas modalidades de complementação: a "modalidade 1", seria referente aos 10\% dos recursos, cuja distribuição continuaria segundo os mesmos critérios atuais: por âmbitos estaduais. A partir daí os recursos acrescentados fariam parte da “modalidade 2", distribuída por rede que não alcançasse o valor aluno ano total. Assim, já no primeiro ano, segundo aquela proposta, dez por cento seriam distribuídos por âmbito estadual, segundo o valor aluno ano do Fundeb e cinco por cento conforme o valor aluno ano total. Nos anos subsequentes, todos os acréscimos seriam distribuídos conforme o VAAT, até que vinte por cento respeitassem esse critério e dez por cento o critério antigo. A partir da complementação da União de 15\%, nenhum âmbito estadual perderia, em relação à situação atual, embora internamente fossem feitas redistribuições. A existência desse modelo híbrido foi pensada, inicialmente, de uma perspectiva pragmática, para evitar resistência de potenciais perdedores de recursos que Ihes eram transferidos via complementação da União. Assim, na segunda minuta a partir do entendimento de que deve haver a distribuição que atenda ao critério do VAAT prevê-se sua adoção total e imediata.

Há, contudo outro ângulo que merece consideração, inicialmente apresentado pela Campanha Nacional pelo Direito à Educação: há redes que, por todos esses anos, instalaram seus sistemas contando com esses recursos, construíram carreiras e sustentam infraestruturas e perdê-los poderia trazer-Ihes sérias dificuldades. Ao mesmo tempo, como tem pontuado o consultor legislativo Alisson Capuzzo, um grande sacrifício de algumas redes não teria um impacto grande em benefício das outras, dada a pulverização. Aduzo que poderia, potencialmente, desorganizar sistemas organizados, sem beneficiar de fato outros. Enquanto apenas dezoito reais por aluno seriam acrescidos às redes beneficiadas, milhões escoariam de redes complexas como as das capitais do Nordeste. 
Uma possibilidade para enfrentar esse dilema é a fixação de transição, tão longa quanto necessário, até a adoção do modelo do VAAT pleno, período em que, por exemplo, os dados do Simulador de Custo-Aluno Qualidade (SIMCAQ) poderiam orientar o ritmo e a forma da transição.

Outra, que parece gerar menos instabilidade, seria a volta ao modelo híbrido, de sorte que, ao fim do processo, dez por cento da complementação obedeceria às regras atuais, mas outros vinte ou trinta adotariam o critério do VAAT.

\section{CONSIDERAÇÕES FINAIS}

Ainda que não se alcance um modelo perfeito, se mantidos os rumos traçados pela Comissão Especial da Câmara e delineados pelos substitutivos da relatora desta Comissão, Deputada Professora Dorinha Seabra Rezende, poderá haver um novo Fundeb mais potente na redistribuição e nos seus resultados. A proposta, aqui exposta, traz importantes princípios: planejamento na ordem social e proibição do retrocesso. A estes princípios se somam outros, também propostos pela relatora citada: responsabilidade solidária e o custo aluno qualidade, como referência para o padrão mínimo definido nacionalmente. Além destes, propõe a ação redistributiva entre as escolas de cada rede e, assim, a direção para um novo Fundeb mais potente na redistribuição e nos resultados porque aprimora o próprio princípio equitativo do Fundo, bem como renova mecanismos para maior solidariedade federativa.

\section{REFERÊNCIAS}

ABRUCIO, Fernando Luiz. A dinâmica federativa da educação brasileira: diagnóstico e propostas de aperfeiçoamento In: PORTELA, Romualdo de Oliveira e SANTANA, Wagner (Orgs.). Educação e federalismo no Brasil: combater as desigualdades, garantir a diversidade. Brasília: UNESCO, 2010.

ANTUNES, Carmen Lúcia Rocha. Constituição e mudança constitucional: limites ao exercício do poder de reforma constitucionais. Brasília: Revista de Informação Legislativa, n 30, 1993.

ARAÚJO, Herton Ellery, CODES, Ana; UDERMAN, Leonardo. O IDEB como instrumento de gestão para uma educação de qualidade - a educação brasileira vista pelas lentes do IDEB. Texto para Discussão2474. Brasília: IPEA, maio de 2019 
ARAUJO, Luiz. O federalismo, os fundos na educação e a diminuição das

desigualdades, p. 49-63. In: Revista Retratos da Escola v.6, n.10, janeiro a junho de 2012. Brasília: CNTE. Dossiê Federalismo e Educação.

O CAQ e o novo papel da União no financiamento da educação

básica. Jundiaí: Paco Editorial, 2016.

Associação Brasileira de Educação (ABE). O problema educacional e a nova

Constituição. São Paulo: Companhia Editora Nacional, 1934.

Associação Nacional de Pós-Graduação e Pesquisa em Educação (Anped). 22/04/2019. http://www.anped.org.br/news/manifesto-pela-manutencao-da-vinculacao-de-verbas-para-educacao-publica-na-constituicao-federal. Acesso em: 14 de julho de 2019

BEDÊ, Fayga Silveira. Sísifo no limite do imponderável. In: BONAVIDES, PauIo, LIMA, Francisco Gérson Marques de BEDÊ, Fayga Silveira. Coords. Constituição e Democracia. Estudos em homenagem ao Professor J.J. Gomes Canotilho. São Paulo: Malheiros, 2006.

BEISIEGEL, Celso. A qualidade do ensino na escola pública. Brasília. Liber Livro, 2006.

BOTELHO, Fernando Neto. As telecomunicações e o Fust. Belo Horizonte: Del Rey, 2001.

BRASIL. Câmara dos Deputados. Comissão Especial destinada a proferir parecer à Proposta de Emenda à Constituição n. ${ }^{15-A}$, de 2015. $4^{a}$ reunião ordinária - reunião n. : 0054/17 - Audiência pública. Sessão de 7 mar. 2017. Brasília, 2017. Notas Taquigráficas. Disponível em: www.camara.leg.br. Acesso em: 14 de julho de 2019.

Emenda Constitucional n 53, de 19 de dezembro de 2006. Dá nova redação aos arts. 7 , 23, 30, 206, 208, 211, 212 da Constituição Federal, e ao art. 60 do Ato das Disposições Constitucionais Transitórias. Disponível em: www.planalto.gov.br. Acesso em: 14 de julho de 2019.

Emenda Constitucional n 59, de 11 de novembro de 2009. Acrescenta $\S 3^{\circ}$ ao art. 76 do Ato das Disposições Constitucionais Transitórias [...] e dá nova redação ao $\S 4^{\circ}$ do art. 211 e ao $\S 3^{\circ}$ do art. 212 e ao caput do art. 214, com a inserção neste dispositivo de inciso VI. Disponível em: www.planalto.gov.br. Acesso em: 14 de julho de 2019.

Relatório Final. GT CAQ Portaria MEC n 459, de 12 de maio de 2015. Brasília, outubro de 2015. 
639.337.Relator, Ministro Celso de Mello.

CROZATTI, Jaime. Ensino Fundamental no Brasil: a Média do gasto por aluno, o IDEB e sua Correlação nos Municípios Brasileiros. XXXV encontro da Anpad, 2011.

DOURADO, Luiz Fernandes (Coordenador); OLIVEIRA, João Ferreira de; SANTOS, Catarina de Almeida. A Qualidade da Educação: conceitos e definições. Brasília: Inep/MEC - Instituto Nacional de Estudos e Pesquisas Educacionais Anísio Teixeira, 2007,65 p. (Série Documental. Textos para Discussão).

FERNANDES, Reynaldo; GREMAUD, Amaury. Qualidade da Educação: Avaliação, Indicadores e Metas. In: VELOSO, Fernando [et al.]. Educação Básica no Brasil: construindo o país do futuro. Rio de Janeiro: Elsevier, 2009.

Qualidade da educação: avaliação, indicadores e metas. Disponível em: https://www.cps.fgv.br/ibrecps/rede/seminario/reynaldo_paper.pdf. Acesso em: 14 de julho de 2019.

HARADA, Kiyoshi. Direito Financeiro e Tributário. $7^{a}$ edição. São Paulo: Ed. Atlas, 2001.

MADURO JUNIOR, Paulo Rogério Rodrigues. Taxas de matrícula e gastos em educação no Brasil. Dissertação submetida à Escola de Pós-Graduação em Economia da Fundação Getúlio Vargas. Rio de Janeiro, 2007.

MARTINS, Paulo de Sena. O financiamento da educação básica como política pública. Revista Brasileira de Política e Administração da Educação, Porto Alegre, v. 26, n. 3, p. 497-514, set. /dez.2010.

FUNDEB, Federalismo e regime de colaboração. Campinas: Autores Associados, 2011.

O direito à educação na Carta Cidadã. Revista de Informação Legislativa-RIL Brasília a. 56, n. 22, p. 223-246. jan./mar. 2019.

MARTINS, Paulo de Sena; PINTO, José Marcelino de Rezende. Como seria o financiamento de um Sistema Nacional de Educação na perspectiva do Manifesto dos Pioneiros da Educação Nova. Jornal de Políticas Educacionais, Curitiba, n. 14, p. 3-16, jul./dez. 2013.

MELLO, Ediruald de; COSTA, Messias. Padrões Mínimos de Oportunidades Educacionais: Uma Proposta. R. bras. list. pedag. Brasília, v.7-1, n.l, p. 1-24, jan./ abr. 1993. 
OLIVEIRA, Mariano Laio de; RODRIGUES, Elenita Gonçalves; SOUZA, Marcelo Lopes de. Efeito Supletivo do Fundeb via complementação da União: análise das receitas dos Valores Anuais por Aluno (VAA) efetivos (2007 a 2014). Textos para discussão, 40.Brasília-DF. Inep/MEC.2015.

PERES, Alexandre José de Souza, SOUZA, Marcelo Lopes de, ALVES, Fabiana de Assis; RODRIGUES, Elenita Gonçalves. Efeito redistributivo intraestadual do Fundeb: uma análise a partir de variáveis financeiras, socioeconômicas e educacionais dos municípios. Brasília-DF. Textos para discussão, 39. Inep/ MEC.2015.

SENA, Paulo. O Financiamento da Educação de Qualidade. Revista Educação e Políticas em Debate, v. 3, n.2, ago. /dez. 2014.

SILVA, Agnaldo Batista da; NASCIMENTO, João Carlos Hipólito Bernardes do; FERREIRA, Augusta da Conceição Santos; SANTOS, Leidiane da Silva. Determinantes do IDEB: um estudo empírico com a Receita Corrente Líquida. Congresso de Contabilidade 2015. UFSC/Universidade de Valencia.

SILVA, José Afonso da. Curso de Direito Constitucional, 19a edição. São PauIo: Malheiros, 2001.

Comentário contextual à Constituição (6 $6^{a}$ edição. São Paulo: MaIheiros, 2009.

SIMÕES, Armando Amorim. As metas de universalização da educação básica no Plano Nacional de Educação: o desafio do acesso e a evasão dos jovens de famílias de baixa renda no Brasil. PNE em movimento 4. Brasília: INEP/MEC, 2016.

SOARES, José Francisco; XAVIER, Flávia Pereira. Pressupostos Educacionais e Estatísticos do IDEB. Educ. Soc., Campinas, v. 34, n. 124, p. 903-923, jul./set. 2013. Disponível em: http://www.cedes.unicamp.br. Acesso em: 14 de julho de 2019.

TANNO, Cláudio. Nota Técnica n 14/2019 - Novo Fundeb e sustentabilidade fiscal: possibilidades de acréscimos na complementação da União. CONOF/ CD. Maio/2019. Disponível em: http://www.camara.leg.br.Acesso em: 14 de juIho de 2019.

Estudo Técnico n²4/2017-CONOF/CD (Outubro/2017). Disponível em:http://www.camara.leg.br.Acesso em: 14 de julho de 2019.

Recebido em: 10 setembro de 2019.

Aprovado em: 12 dezembro de 2019. 